\title{
Reducing the Cost of Laparoscopy: Reusable versus Disposable Laparoscopic Instruments
}

\author{
Dimitrios K. Manatakis and Nikolaos Georgopoulos \\ 2nd Surgical Department, Athens Naval and Veterans Hospital, 70 Deinokratous Street, 11521 Athens, Greece \\ Correspondence should be addressed to Dimitrios K. Manatakis; dmanatak@yahoo.gr
}

Received 22 February 2014; Accepted 16 July 2014; Published 22 July 2014

Academic Editor: Chin-Jung Wang

Copyright (C) 2014 D. K. Manatakis and N. Georgopoulos. This is an open access article distributed under the Creative Commons Attribution License, which permits unrestricted use, distribution, and reproduction in any medium, provided the original work is properly cited.

\begin{abstract}
Cost-effectiveness in health care management is critical. The situation in debt-stricken Greece is further aggravated by the financial crisis and constant National Health System expense cut-downs. In an effort to minimize the cost of laparoscopy, our department introduced reusable laparoscopic instruments in December 2011. The aim of this study was to assess potential cost reduction of laparoscopic operations in the field of general surgery. Hospital records, invoice lists, and operative notes between January 2012 and December 2013, were retrospectively reviewed and data were collected on laparoscopic procedures, instrument failures, and replacement needs. Initial acquisition cost of 5 basic instrument sets was $€ 21,422$. Over the following 24 months, they were used in 623 operations, with a total maintenance cost of $€ 11,487$. Based on an average retail price of $€ 490$ per set, projected cost with disposable instruments would amount to $€ 305,270$, creating savings of $€ 272,361$ over the two-year period under study. Despite the seemingly high purchase price, each set amortized its acquisition cost after only 9 procedures and instrument cost depreciated to less than $€ 55$ per case. Disposable instruments cost 9 times more than reusable ones, and their high price would almost equal the total hospital reimbursement by social security funds for many common laparoscopic procedures.
\end{abstract}

\section{Introduction}

The wide adoption of the concept of minimally invasive laparoendoscopic surgery and the concomitant progress in technology have reduced the prices of sophisticated laparoscopic instruments; however, cost of laparoscopy remains generally higher than that of open surgery. In most clinical studies, higher operating theatre cost is partly offset by shorter hospital stays, less medication requirements, shorter periods of convalescence, and faster return to work and normal activity [1-6]. On the other hand, multiple cost studies, already from the 1990s, have shown that reusable laparoscopic instruments (RLIs) are a valuable asset for surgical departments in terms of cost reduction [7-15].

In an effort to minimize the cost of laparoscopic surgery, without compromising quality of health services, our department introduced RLIs in December 2011, under the pressure of budget limitation. The primary aim of this study was to assess potential cost reduction of laparoscopic procedures performed between January 2012 and December 2013, in the field of general surgery. The secondary aim was to calculate annual maintenance expenses of RLIs and investigate possible ways of further cost limiting.

\section{Materials and Methods}

Hospital records, invoice lists, and operative notes between January 2012 and December 2013 were retrospectively reviewed and data were collected on type and number of laparoscopic operations, instrument failures, and replacement requirements. Maintenance cost was calculated as the sum of resterilization, repackaging, repair, and replacement expenses. For comparison purposes, retail prices of disposable laparoscopic instruments (DLIs) were obtained from the National Price Observatory for Health Supplies. Disposal cost for DLIs, based on weight of waste, was practically negligible.

Cost of insufflation and suction-irrigation tubes, clip appliers, retrieval bags, mesh patches, staplers, and so forth, was not included in the analysis, since there is no choice between reusable and disposable forms. 
TABLE 1: Laparoscopic operations between January 2012 and December 2013 .

\begin{tabular}{lc}
\hline Operation & $n$ \\
\hline Cholecystectomy & 454 \\
Appendicectomy & 42 \\
Hernia repair & 10 \\
Nissen fundoplication & 16 \\
Colectomy & 33 \\
Adjustable gastric band & 16 \\
Vertical sleeve gastrectomy & 20 \\
Gastric plication & 2 \\
Heller's myotomy & 1 \\
Ventral rectopexy & 1 \\
Hepatic cyst unroofing & 2 \\
Exploratory/staging/biopsy & 26 \\
\hline Total & 623 \\
\hline
\end{tabular}

\section{Results}

In December 2011, 5 basic sets of RLIs were purchased (AESCULAP, B-BRAUN, Tuttlingen, Germany), with initial acquisition cost of $€ 21,422$. Each set consists of a curved monopolar dissector, two atraumatic grasp monopolar forceps with ratchet, a pair of Metzenbaum monopolar scissors, a suction-irrigation device, a Veress needle, a Hasson cannula, and two $12 \mathrm{~mm}$ and two $5 \mathrm{~mm}$ bladeless trocars with replaceable rubber valves. Over the following 24 months, they were used in 623 laparoscopic operations (Table 1), covering a wide range of upper and lower GI tract pathologies and obesity.

Two-year maintenance cost amounted to $€ 11,487$. Resterilization and repackaging of each set were calculated at $€ 5$ per procedure, costing $€ 3,115$ for the two-year period under study, while replacement and repair costs came to $€ 8,372$, with requirements limited to torn trocar valves and a broken grasper forceps (Table 2). Trocar valves were replaced after an average of 10 procedures, while scissors were sent for sharpening after $60-80$ operations.

Based on an average retail price of $€ 490$ per set, estimated cost of 623 procedures with DLIs would come to $€ 305,270$. The actual total instrument cost was $€ 32,909$, creating savings of $€ 272,361$ over two years.

\section{Discussion}

Cost-effectiveness in health care management has always been a major issue. The situation in debt-stricken Greece is further aggravated by the financial crisis and constant National Health System expense cut-downs. Hospital administrations are called to drastically reduce their expenditure and use their limited resources wisely.

Our preliminary study of reusable versus disposable laparoscopic instruments, based on a projected number of 200 laparoscopic operations per annum, predicted net yearly savings of around $€ 80,000$. Two years later, the results of this
TABLE 2: Replacement and repair requirements (incl. VAT 23\%).

\begin{tabular}{lccc}
\hline Part & $\begin{array}{c}\text { Number of } \\
\text { units }\end{array}$ & $\begin{array}{c}\text { Price per } \\
\text { unit }(€)\end{array}$ & Price $(€)$ \\
\hline Trocar valve 10-12 mm & 50 & 8.65 & 432.35 \\
Trocar valve 10-12 mm & 56 & 76.20 & $4,267.12$ \\
with 5 mm adaptor & 79 & 12.77 & $1,008.62$ \\
Trocar valve 5 mm & 36 & 70.11 & $2,523.96$ \\
Adaptor & 1 & 139.99 & 139.99 \\
Grasper tip repair & 1 & Gratis & Gratis \\
Scissors sharpening & & Total & 8,372 Euros \\
\hline
\end{tabular}

TABLE 3: Hospital reimbursements by social security funds for common, uncomplicated laparoscopic procedures.

\begin{tabular}{lc}
\hline Operation & Hospital reimbursement $(€)$ \\
\hline Cholecystectomy & 1,085 \\
Appendicectomy & 764 \\
Hernia repair & 868 \\
Nissen fundoplication & 1,649 \\
Colon resection & 2,519 \\
Rectum resection & 3,506 \\
Obesity procedures & 1,506 \\
\hline
\end{tabular}

analysis clearly confirm our expectations. Despite the seemingly high purchase price, each set amortized its acquisition cost after only 9 laparoscopic operations. Initial cost was $65 \%$ of the total two-year expenditure and depreciated to less than $€ 55$ per patient. This figure is expected to fall even more, with every future use of the instruments.

As per annual maintenance cost, roughly $30 \%$ covered the relatively inflexible expenses of resterilization and repackaging, while $70 \%$ pertained to replacements and repairs. Worn-out valves need replacement more often than any other instrument part $[10,12]$. This results in frequent air leaks and higher $\mathrm{CO}_{2}$ volume to maintain the pneumoperitoneum at the desired pressure. We have observed that most of the leaking valves were torn at the rubber seal, a result of forceful insertion/withdrawal of instruments.

The cost analysis revealed more useful conclusions. Laparoscopic instrument cost would be 9 times higher with disposable compared with reusable instruments. More importantly though disposable instrument cost alone would cover almost half of the total hospital reimbursement by social security funds for many common laparoscopic procedures (Table 3) [16].

Further reduction in cost will chiefly result from increasing the number of uses, reflecting the decreasing depreciation cost per case. Expanding use of RLIs in the fields of urology and gynecology would add another 50 to 100 procedures annually. On the other hand, maintenance expenses, at $€ 5,750$ per year, are already quite acceptable and rather fixed.

Much discussion has occurred in the past regarding the advantages and disadvantages of reusable versus disposable instruments [17]. The rationale behind initial skepticism 
against RLIs included not only high acquisition and maintenance cost, but also issues of possible transmission of infectious disease to patients and medical personnel, instrument inefficiency, and lack of durability [18, 19]. However most of these studies date back to the 1990s. With technological progress, newer designs, and appropriate training; these problems, if once existing, are virtually obsolete.

Despite speculative arguments, sterilization proved to be adequate, when manufacturer's instructions are followed, and we could not find any case report in the literature of infectious disease transmission through inadequately processed RLIs $[7,9,20]$. The only difference that we detected was that mechanized cleaning systems are reported to be more efficient and safer than manual washing [21]. The cheap alternative of resterilizing single-use instruments may be feasible but is generally not advised [9, 22-25]. These instruments are not designed to be disassembled and dead spaces inside the instrument may harbor residual debris, which are difficult to remove between procedures. This makes the surgeon ultimately responsible for any mishap, raising ethical and juridical concerns.

Modular configuration, adopted by most manufacturers, permits dismantling of the instruments, while maintaining a simple yet robust design. Thus repairs are facilitated, since only the faulty part can be replaced, with minimal cost. Moreover, access is allowed throughout the shaft and the handle, allowing for optimal cleaning and effective sterilization.

Skeptics also voice that ergonomics and efficacy of DLIs are unequaled, since they are "new" every time and this may indeed be true up to a point. Reusable instruments are more prone to technical issues but should be considered an investment for every surgical department and with careful handling and maintenance, the normal wear and tear can be kept to a minimum [15]. Other than a broken grasper working tip, due to an accidental fall to the ground, we had no major instrument failures. A hybrid model of reusable instruments backed up by a small number of disposable ones, for immediate availability in cases of technical problems, appears as the optimal solution, balancing cost-effectiveness with reliability [10].

Next to trocar valves that required replacement every 10 procedures, scissors needed sharpening after $60-80$ operations, whereas bladeless trocars do not require sharpening at all. Reusable trocars possibly require more force during insertion and this could be associated with more intraabdominal injuries [26]. Our team has not observed any visceral or vascular injuries with either the Veress or the Hasson approach. Irrespectively of trocar design, it is imperative always to insert the trocars under direct vision, to minimize risk of damaging abdominal organs.

Another cause of collateral damage is electrosurgical injuries due to insulation failure. We routinely check insulation sheaths macroscopically for signs of wear; however, our institution lacks the facility to perform proper electrical conductivity tests on the instruments. Based on the literature, one in five RLIs has some kind of insulation defect, which tends to occur more often at the distal third of the sheath, near the working tip $[27,28]$. Insulation problems have also been recorded with $3 \%$ of DLIs [27]. Electrosurgical injuries, especially in anatomic areas with delicate structures, may go undetected for months after surgery and are the cause of medicolegal actions [29].

Last but not least, increasing environmental concerns are not to be taken lightly [7, 13, 14, 30]. Laparoscopic instruments are manufactured using materials potentially hazardous to the environment. Additionally, plastic packaging results in large volume of unnecessary hospital waste. Surprisingly, we discovered that disposal cost of DLIs, based on their weight as waste, is practically negligible, compared to their purchase price [13]. However their impact on the environment is far greater than their impact on hospital budgets.

Cost studies of this type have a certain limitation. Our comparative analysis is based on specific retail prices for DLIs, obtained by the National Price Observatory. Suppliers of instruments may offer favorable pricing packages through individual agreements, when larger quantities are ordered [6]. Therefore our findings cannot be directly extrapolated to other institutions. However this study showed that RLIs have a clear financial advantage over the single-use platform. Choice of one over the other modality lies ultimately with the surgeon and should be guided not only by personal preference or habit, but also by cost-effectiveness [16, 31]. As Dr. Winter of the Institute for Clinical Outcomes Research and Education eloquently wrote, "most of our modern disposable (and expensive) laparoscopic paraphernalia are non-essential luxuries. Reusable trocars and non-disposable instruments are often adequate, if not ideal" [1].

The fact remains though that instrumentation cost is only a fraction of total hospital costs per patient [17]. For a sustainable health care management, a comprehensive approach to cost-effectiveness should also combine ambulatory protocols, targeted preoperative patient assessment, and standardized enhanced recovery pathways.

\section{Conclusion}

Reusable laparoscopic instruments substantially reduce the cost of laparoscopic surgery, without compromising safety of patients and medical personnel. Initial acquisition costs are quickly amortized and further depreciated with every use. Although they may be prone to more technical issues compared to disposable instruments, they should be considered an investment for surgical departments and handled with proper care and attention.

\section{Conflict of Interests}

The authors declare that there is no conflict of interests regarding the publication of this paper.

\section{References}

[1] D. C. Winter, "The cost of laparoscopic surgery is the price of progress," British Journal of Surgery, vol. 96, no. 4, pp. 327-328, 2009.

[2] D. E. Moore, T. Speroff, E. Grogan, B. Poulose, and M. D. Holzman, "Cost perspectives of laparoscopic and open 
appendectomy," Surgical Endoscopy and Other Interventional Techniques, vol. 19, no. 3, pp. 374-378, 2005.

[3] M. S. L. Ljem, J. A. M. Halsema, Y. D. van der Graaf, A. J. P. Schrijvers, and T. J. M. V. Van Vroonhoven, "Cost-effectiveness of extraperitoneal laparoscopic inguinal hernia repair: a randomized comparison with conventional herniorrhaphy," Annals of Surgery, vol. 226, no. 6, pp. 668-676, 1997.

[4] F. Keus, T. de Jonge, H. G. Gooszen, E. Buskens, and C. J. H. M. van Laarhoven, "Cost-minimization analysis in a blind randomized trial on small-incision versus laparoscopic cholecystectomy from a societal perspective: sick leave outweighs efforts in hospital savings," Trials, vol. 10, p. 80, 2009.

[5] T. Heikkinen, K. Haukipuro, P. Koivukangas et al., "Comparison of costs between laparoscopic and open nissen fundoplication: a prospective randomized study with a 3-month followup," Journal of the American College of Surgeons, vol. 188, no. 4, pp. 368-376, 1999.

[6] E. Yung, M. Gagner, A. Pomp, G. Dakin, L. Milone, and G. Strain, "Cost comparison of reusable and single-use ultrasonic shears for laparoscopic bariatric surgery," Obesity Surgery, vol. 20, no. 4, pp. 512-518, 2010.

[7] K. N. Apelgren, M. L. Blank, C. A. Slomski, and N. S. Hadjis, "Reusable instruments are more cost-effective than disposable instruments for laparoscopic cholecystectomy," Surgical Endoscopy, vol. 8, no. 1, pp. 32-34, 1994.

[8] G. N. Schaer, O. R. Koechli, and U. Haller, "Single-use versus reusable laparoscopic surgical instruments: a comparative cost analysis," American Journal of Obstetrics and Gynecology, vol. 173, no. 6, pp. 1812-1815, 1995.

[9] L. Demoulin, K. Kesteloot, and F. Penninckx, "A cost comparison of disposable vs reusable instruments in laparoscopic cholecystectomy," Surgical Endoscopy, vol. 10, no. 5, pp. 520-525, 1996.

[10] G. Eddie and S. White, "A comparison of reusable versus disposable laparoscopic instrument costs," Australian and New Zealand Journal of Surgery, vol. 66, no. 10, pp. 671-675, 1996.

[11] T. W. Fengler, H. Pahlke, and E. Kraas, "Sterile and economic instrumentation in laparoscopic surgery: Experiences with 6,000 surgical laparoscopies, 1990-1996," Surgical Endoscopy, vol. 12, no. 10, pp. 1275-1279, 1998.

[12] H. Lau, F. Lee, N. G. Patil, and W. K. Yuen, “Two hundred endoscopic extraperitoneal inguinal hernioplasties: cost containment by reusable instruments," Chinese Medical Journal, vol. 115, no. 6, pp. 888-891, 2002.

[13] S. Adler, M. Scherrer, K. D. Rückauer, and F. D. Daschner, "Comparison of economic and environmental impacts between disposable and reusable instruments used for laparoscopic cholecystectomy," Surgical Endoscopy and Other Interventional Techniques, vol. 19, no. 2, pp. 268-272, 2005.

[14] M. Slater, M. I. Booth, and T. C. B. Dehn, "Cost-effective laparoscopic cholecystectomy," Annals of the Royal College of Surgeons of England, vol. 91, no. 8, pp. 670-672, 2009.

[15] N. Vasios, M. Verroiotou, G. Komninos, S. Arapoglou, and G. Fragandreas, "Study of the cost of mainly reusable equipment for laparoscopic cholecystectomy," Hellenic Journal of Surgery, vol. 85, no. 2, pp. 101-104, 2013.

[16] T. Chu, R. A. Chandhoke, P. C. Smith, and S. D. Schwaitzberg, "The impact of surgeon choice on the cost of performing laparoscopic appendectomy," Surgical Endoscopy and Other Interventional Techniques, vol. 25, no. 4, pp. 1187-1191, 2011.
[17] L. W. Traverso and K. Hargrave, "A prospective cost analysis of laparoscopic cholecystectomy," The American Journal of Surgery, vol. 169, no. 5, pp. 503-506, 1995.

[18] B. V. MacFadyen and S. Lenz, "The economic considerations in laparoscopic surgery," Surgical Endoscopy, vol. 8, no. 7, pp. 748$752,1994$.

[19] M. Reichert, "Laparoscopic instruments. Patient care, cost issues," AORN Journal, vol. 57, no. 3, pp. 637-655, 1993.

[20] E. M. Targarona, C. Balagué, M. M. Knook, and M. Trías, "Laparoscopic surgery and surgical infection," British Journal of Surgery, vol. 87, no. 5, pp. 536-544, 2000.

[21] M. J. Alfa and R. Nemes, "Manual versus automated methods for cleaning reusable accessory devices used for minimally invasive surgical procedures," Journal of Hospital Infection, vol. 58, no. 1, pp. 50-58, 2004.

[22] D. Dunn, "Reprocessing single-use devices-the ethical dilemma," AORN Journal, vol. 7, no. 5, pp. 988-999, 2002.

[23] C. D. L. Botero Couto Lopes, K. U. Graziano, and T. D. J. Andreoli Pinto, "Evaluation of single-use reprocessed laparoscopic instrument sterilization," Revista Latino-Americana de Enfermagem, vol. 19, no. 2, pp. 370-377, 2011.

[24] J. DesCôteaux, E. C. Poulin, M. Julien, and R. Guidoin, "Residual Organic Debris on Processed Surgical Instruments," AORN Journal, vol. 62, no. 1, pp. 23-30, 1995.

[25] K. Roth, P. Heeg, and R. Reichl, "Specific hygiene issues relating to reprocessing and reuse of single-use devices for laparoscopic surgery," Surgical Endoscopy and Other Interventional Techniques, vol. 16, no. 7, pp. 1091-1097, 2002.

[26] C. J. Kelty, P. A. Super, and C. J. Stoddard, "The driving force in trocar insertion: a comparison between disposable and reusable trocars," Surgical Endoscopy, vol. 14, no. 11, pp. 1045-1046, 2000.

[27] P. N. Montero, T. N. Robinson, J. S. Weaver, and G. V. Stiegmann, "Insulation failure in laparoscopic instruments," Surgical Endoscopy and other Interventional Techniques, vol. 24, no. 2, pp. 462-465, 2010.

[28] I. Alkatout, T. Schollmeyer, N. A. Hawaldar, N. Sharma, and L. Mettler, "Principles and safety measures of electrosurgery in laparoscopy," Journal of the Society of Laparoendoscopic Surgeons, vol. 16, no. 1, pp. 130-139, 2012.

[29] Q. Liu and X. Sun, "Indirect electrical injuries from capacitive coupling: a rarely mentioned electrosurgical complication in monopolar laparoscopy," Acta Obstetricia et Gynecologica Scandinavica, vol. 92, no. 2, pp. 238-241, 2013.

[30] S. Ibbotson, T. Dettmer, S. Kara, and C. Herrmann, "Ecoefficiency of disposable and reusable surgical instruments-a scissors case," International Journal of Life Cycle Assessment, vol. 18, no. 5, pp. 1137-1148, 2013.

[31] L. W. Traverso, "The laparoscopic surgical value package and how surgeons can influence costs," Surgical Clinics of North America, vol. 76, no. 3, pp. 631-639, 1996. 


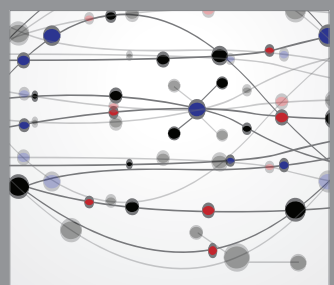

The Scientific World Journal
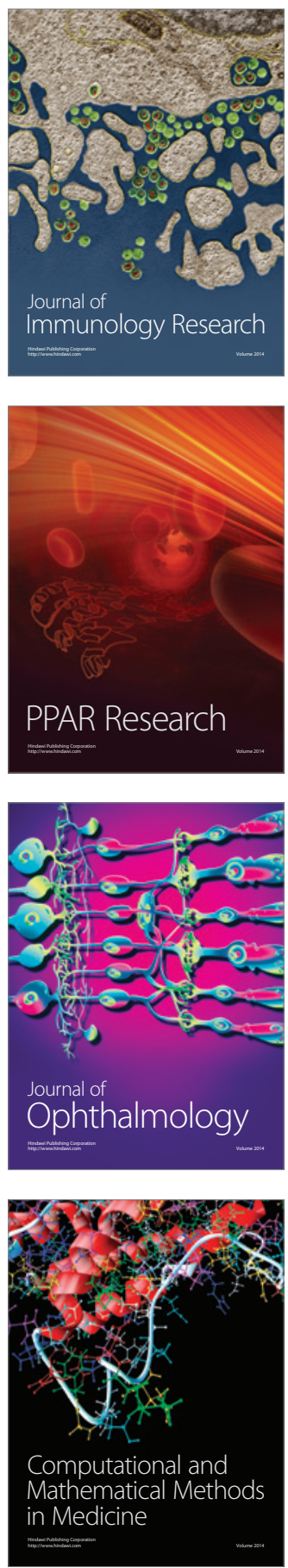

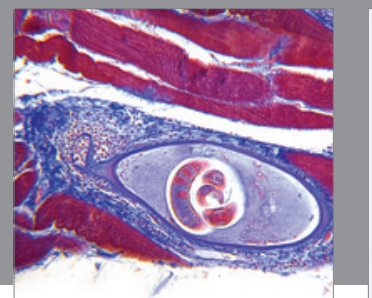

Gastroenterology

Research and Practice
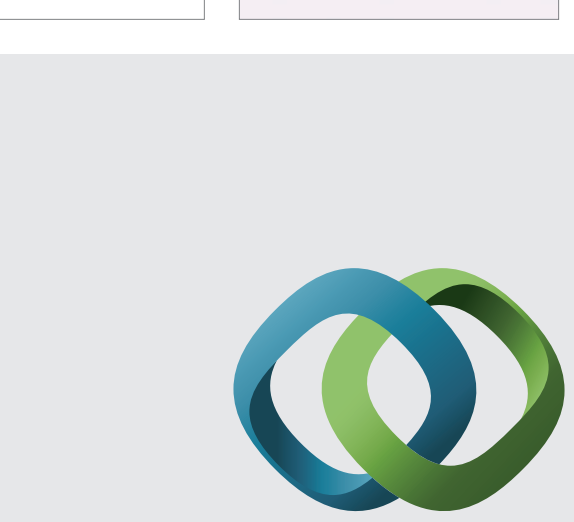

\section{Hindawi}

Submit your manuscripts at

http://www.hindawi.com
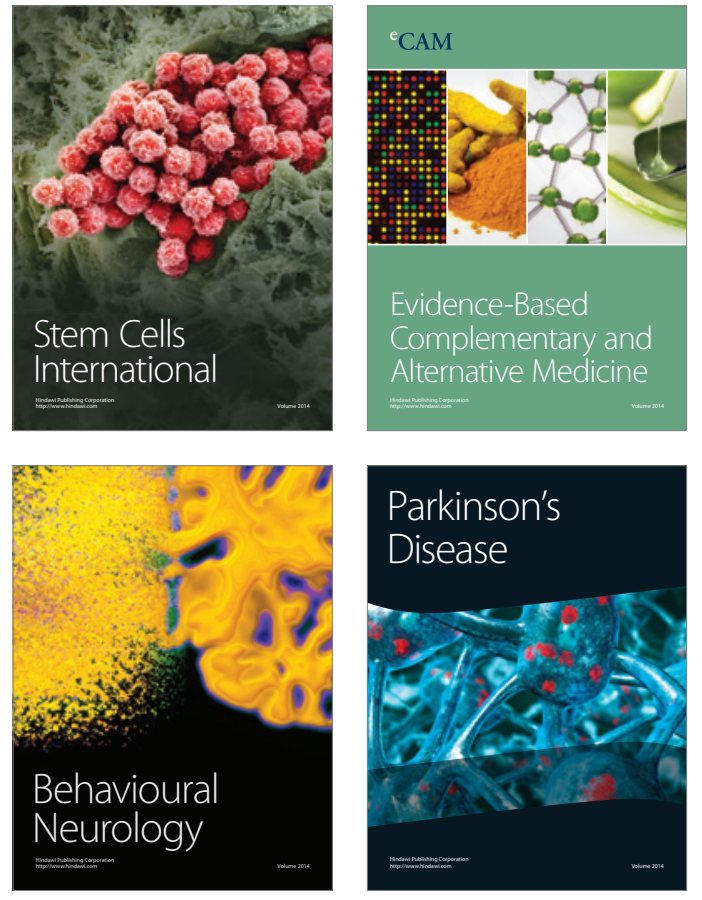
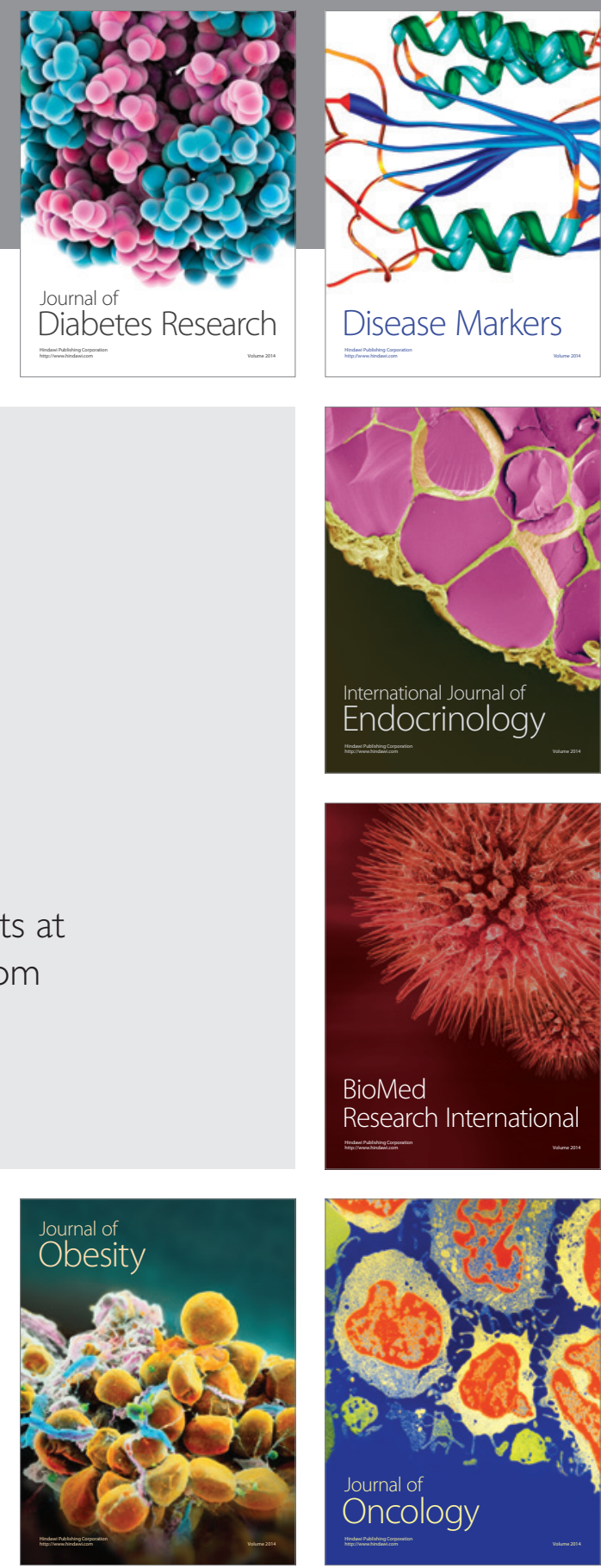

Disease Markers
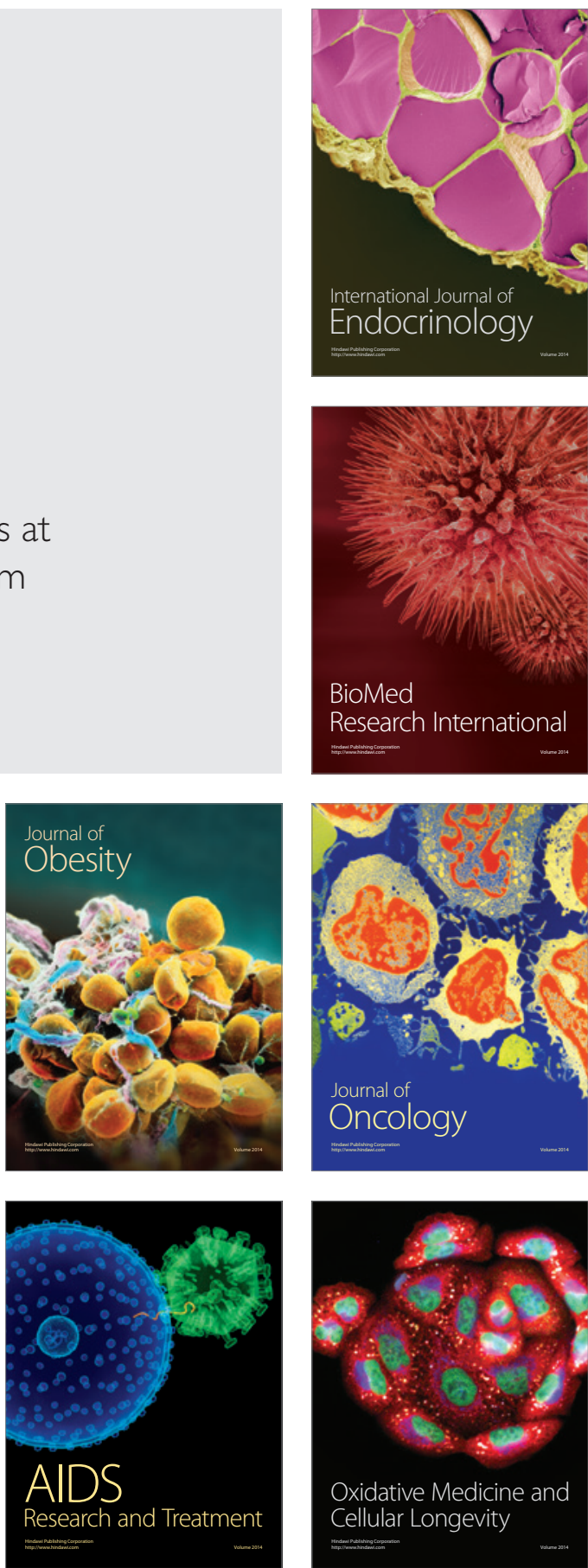